\title{
Complex Cyst of Kidney
}

National Cancer Institute

\section{Source}

National Cancer Institute. Complex Cyst of Kidney. NCI Thesaurus. Code C123170.

A heterogeneous and/or septated cyst located in the kidney. 